\title{
JAN AMOS COMENIUS: \\ VIGENCIA Y MODERNIDAD DE UN PENSADOR UNIVERSAL DE LA EDUCACIÓN
}

\section{Introducción}

Situada en la espléndida y aristocrática zona de la ciudad Praga conocida como Malá Strana, aquella construcción no provoca a primera vista la atención. Sólo si se observa con mayor detalle se nota una diminuta placa que nos indica que estamos frente al Museo Pedagógico dedicado a Jan Amos Komensky, cuyo apellido latinizado como Comenius o en español Comenio quizás conozcamos mejor.

¿Quién es Jan Amos Komensky? Esta simple pregunta nos impulsa a un ejercicio intelectual para desentrañar o más bien intentar una relectura del corpus de ideas y aportes de este gran pedagogo y filósofo checo.

Aprovechamos para este ejercicio dos hechos importantes. El primero es la reciente conmemoración de los 350 años desde la publicación en Amsterdam de su colección de obras pedagógicas denominada "Opera didactica omnia", un hito clave en la evolución de los sistemas y prácticas pedagógicas en nuestra civilización, y el segundo se centra en Chile: el Quo vadis del sistema de educación firmemente instalado en la agenda pública.

Los diversos actores del sistema educacional chileno han planteado críticas profundas y se han expresado en movilizaciones exigiendo una educación que garantice calidad, equidad, totalidad, igualdad de oportunidades y no discriminación, entre otras. La fuerza de estas reivindicaciones, compartidas por un alto porcentaje de ciudadanos, obliga a plantear nuevamente los ejes centrales por los cuales transitar en esta reforma al sistema de educación (en todos sus niveles). Este replantear involucra la búsqueda de nuevas ideas, pero también la revisión de las de pensadores clásicos, revitalizando y profundizando en nuevas ópticas del problema. 
Ante la rápida evolución y crítica de los paradigmas educacionales que mantienen en continuo cuestionamiento el modelo educativo implementado en Chile, una mirada retrospectiva y serena al pensamiento de Comenius contribuirá sin duda al debate.

\section{Comenius y su tiempo}

En uno de los rincones más alejados del reino checo en 1592, al sureste de Moravia, una región aún conocida por sus colinas, praderas y excelentes viñedos, nace el reformador humanista, obispo protestante, filósofo y pedagogo Jan Amos Komensky. Su nombre se latinizó como Comenius y de allí pasó al español como Comenio. De la milenaria y poco conocida historia de la República Checa es quizás uno de los pensadores que aún mantiene un gran peso dentro de la cultura occidental.

En los años en que vivió Comenius, la región de Moravia era conocida por su tolerancia religiosa; la mayoría de sus habitantes, incluyendo a los padres de Comenius, eran protestantes y pertenecían a la pequeña pero influyente "Hermandad de Moravia", una congregación religiosa formada bajo los principios del teólogo checo Jan Hus, líder del movimiento reformador y revolucionario de los Husitas (Cornej y Pokorný, 2000).

Hus había anticipado la reforma alemana de Lutero en más de una centuria, al criticar al clérigo en el siglo XV. El llamaba a la Iglesia a reconocer la igualdad entre el clero y los creyentes comunes y a compartir la comunión en ambos casos. Su criticismo y propuestas lo llevaron finalmente a ser quemado en la estaca en 1415, a orillas del lago Constanza en la actual Suiza, iniciando una revolución social y espiritual en los países checos que duraría seis cruzadas papales (Cornej y Pokorný, 2000). A pesar de que la situación se calmó cerca del siglo XVI, las tierras checas permanecieron divididas en su fe, con los católicos, a pesar de ser minoritarios, rigiendo sobre la mayoritaria población protestante. La libertad religiosa, sin embargo, continuó por algunos años (Tenenti y Romano, 1983). 
En ese ambiente creció Comenius. Bajo el alero de la hermandad de Moravia recibió su educación y fue conducido hacia el sacerdocio, estudiando en las ciudades de Presov, en Moravia, y más tarde en Herborn y Heidelberg, en Alemania, donde fue introducido en la tradición humanista europea. Sus tutores fueron Johann Heinrich Alsted, Johann Fischer-Piscator y David Pareus. Estos educadores ejercieron una profunda influencia sobre el pensamiento de Comenius. Alsted, por ejemplo, propugnaba que el conjunto del conocimiento estuviera en un sistema unificado y claro, una idea que formará parte esencial del pensamiento de Comenius (Capek, 1957).

\section{Sus primeras obras}

Comenius regresó a Moravia en 1614, después de sus estudios, a enseñar y ejercer su sacerdocio. Su trabajo como educador y teólogo se reflejó en el libro "El teatro de todas las cosas", la primera enciclopedia que incluyó un tratado de gramática checa.

A través de estos textos se desarrollan sus primeros esfuerzos para unificar las piezas del puzzle humano, que él consideraba como parte de un todo armonioso y finalmente de una unidad perfecta. Esta senda de trabajo y pensamiento se ve abruptamente frenada. No sólo para él sino para toda la nación checa se avecinan tiempos difíciles. Las relaciones entre los Estados Checos y la dinastía de los Habsburgo se deterioran luego que los estados protestantes, aduciendo una persecución creciente de parte de la minoría católica, deponen al Rey Fernando II. Ello tiene como consecuencia protestas que, eventualmente, inician la guerra de los treinta años. Un hecho que gatilla esta guerra es la "Defenestración de Praga". Aquel evento en el cual dos representantes católicos son arrojados desde lo alto de una ventana en el Castillo de Praga (Tenenti y Romano, 1983). La respuesta de los católicos no se hace esperar.

El 8 de noviembre de 1620 se desarrolla en las afueras de Praga la decisiva Batalla de la Montaña Blanca (Bilá hora en checo). En ella los protestantes son derrotados definitivamente y ello marca el inicio de la recatolización forzada de las tierras checas. En pocos años los reinos de Bohemia, Moravia y Silesia son controlados con mano dura 
por la dinastía Habsburgo, dominio que continúa por los siguientes 300 años (Cornej y Pokorný, 2000).

El mundo de Comenius comienza a derrumbarse. A la derrota y persecución de sus ideas religiosas se suma la pérdida de su esposa e hijos debido a la plaga que azota a Europa entera. Es en aquella época que comienza la redacción de su último libro en checo, "El laberinto del mundo y el paraíso del corazón”, una visión extremadamente crítica del mundo, las relaciones humanas y su comportamiento. Esta obra es, en primer lugar y principalmente, una alegoría.

Presenta al mundo como un pueblo y a sus habitantes como paisanos, los que han perdido su camino en diferentes laberintos que ellos mismos han fabricado. El narrador es un peregrino acompañado en su viaje por dos "guías" de dudosa utilidad: "Omnipresente" y "Desilusión". A petición del peregrino, los guías lo llevan al pueblo a investigar "todas las cosas bajo el sol". Él espera encontrar no sólo la felicidad sino también un significado para la existencia. El peregrino no encuentra ninguno de éstos, al contrario, sólo descubre los fondos del comportamiento humano: hipocresía, tontería, depravación moral.

"He visto a la muerte cargando una filuda guadaña y un arco, caminando furtivamente entre ellos, amenazante, recordándoles todo el tiempo que son mortales" (Velinger, 2004). Los habitantes no le hacen caso, continuando con su necedad y mala intención. Enfadada, la muerte toma su arco y comienza a arrojar flechas en todas direcciones. Comienzan a caer jóvenes, viejos, pobres o ricos, letrados e ignorantes. Todas las clases sociales, profesiones, toda clase de miseria humana desfila delante del peregrino, quien finalmente declara: "Oh miserables, oh infelices hombres. ¿Es ésta vuestra última gloria? (...) ¿Es este el fin de vuestros estudios y trabajo, de vuestra sabiduría? (...) ¿Es ésta la deseada paz y calma después de tanto trabajo y forcejeos? (...) Oh, cómo quisiera nunca haber nacido" (Velinger, 2004).

En esta primera parte Comenius sugiere que el hombre ha olvidado hacia dónde mirar en la búsqueda de la redención espiritual. 
En la segunda insinúa la posibilidad de la esperanza y renovación. El peregrino regresa a su corazón, primero para estar aislado de la corrupción del mundo, pero también para encontrar consuelo en la transformación y en la ayuda mutua entre los hombres y, de esta forma, hallar una vida llena de significado. En esta segunda parte Comenius señala que la salvación debemos buscarla en nuestro interior, en nuestras almas, en la aceptación redentora de Cristo.

"Mantente en el mundo con tu cuerpo pero conmigo en tu corazón. Si haces aquello serás bendecido y todo será para bien" (Velinger, 2004).

En estos libros revela su eterna esperanza en un mundo mejor. Esta será una constante de su vida y de una parte importante de su legado. Podemos ver en esta actitud de Comenius un claro mensaje y enseñanza para las labores universitarias. Enseña a ser optimista y perseverante en los afanes e ideales, más aún en tiempos convulsionados o difíciles.

Comenius conoció bien las dificultades. En 1623 la ciudad de Fulnek, en cuya parroquia había sido pastor, fue incendiada y junto con ella todos sus libros. En 1628 debió partir al exilio, situación que lo estimuló a desarrollar sus ideas y temas en un complejo sistema práctico y filosófico.

Vivirá y producirá profundos cambios en los sistemas educativos en Inglaterra, Holanda, Suecia, Hungría y Polonia, no regresando jamás a su tierra. De este periodo son sus obras "La gran Didáctica", "La escuela de la infancia", "Abierto el portal de las lenguas", entre otras. Este esfuerzo pedagógico involucrará no sólo aquellos países donde habita, sino también al mundo entero. De allí proviene su apelativo de "profesor de las naciones" con el que se le conoce universalmente.

\section{Su sistema filosófico de educación: Pansofía}

Se trata de un sistema que busca integrar todo el conocimiento por el bien de la humanidad. Una de las primeras obras donde la incorpora 
es "Janua Linguarum Reserata" (Abierto el portal de las lenguas), publicada en 1633, un texto para aprender latín y otras lenguas de una manera sencilla, que se transformó en un bestseller en la Europa de esos años (Velinger, 2004). Comenius presenta un texto en que enriquece el conocimiento real acerca de todo el mundo y este "todo" es uno de los aspectos más relevantes de su forma holística de ver el universo. Enfatiza que la "Pansofía", en el contexto educativo, no sólo debe abarcar contenidos y hechos fácticos, sino también una adecuada introducción y una metodológica acerca del conocimiento del mundo en su conjunto (Denis, 1993).

Esta forma integrada de ver el conocimiento es muy diferente al racionalismo de la Ilustración que impera en su época. Incorpora - estrechamente ligados como base necesaria para el conocimiento, el entendimiento y la sabiduría- no sólo la razón, sino también la experiencia, la revelación espiritual y los valores morales. Esta forma del ver al mundo no podía ser más diferente de aquella que finalmente prevalecería en nuestro mundo occidental: la tradición cartesiana, que consideraba al mundo entero como un mecanismo y al hombre sólo como un observador externo. No concebía al hombre y la naturaleza como una unidad (Schaller, 1989). El pensamiento cartesiano permitió el avance en las ciencias exactas y nuestra sociedad racionalista.

Comenius buscaba una "armonía del todo", entre el macro y el microcosmos. No separaba la razón de la voluntad, de la emoción o del trabajo. Para Comenius la razón pura no es suficiente para entender las motivaciones del hombre (Schaller, 1989).

Para llevar a cabo su gran tarea de "reformar a la humanidad", en concordancia con su ideal pansofista, comprendió la importancia de desarrollar una metodología pedagógica y didáctica, de modo de crear un ambiente más favorable para el aprendizaje de los niños, transformando eventualmente la condición humana. El creía que una "educación para todos" sería el primer paso para un mundo mejor. Un ejemplo de este esfuerzo es la obra "La gran didáctica", cuyo axioma en la portada es: "Enseñar todo a todos los hombres concienzudamente". 
La educación, de acuerdo con Comenius, no es meramente el entrenamiento de los alumnos en las escuelas o en la casa, sino un proceso que afecta a nuestras vidas y a la sociedad en su conjunto, considerada ésta como sub specie educationis (Piaget, 1957). Declara: educación para todos, sin importar la clase social, económica, raza, sexo u otra discriminante; educación sobre todo y desde todos los puntos de vista.

Se trata de un sistema universal con fuertes implicancias democráticas. Anhelaba un sistema educacional único y la obligación de las autoridades de velar por todo su sistema educativo. Era enfático al afirmar que todo niño, independiente de género o estirpe, debe asistir a la escuela y recibir la misma educación como único medio para entender y aceptar la civilización que le rodea.

Este sistema de educación no es utópico; existe, con variaciones, en países Alemania, República Checa, Suiza. Las grandes reformas educativas de la antigua Unión Soviética y de los países de su órbita tomaron también en cuenta los principios comenianos de una educación única y democrática (Frumov, 1953).

Se cuenta entre los primeros en enseñar los idiomas clásicos a través del uso paralelo de textos antiguos y modernos; se cree que su libro "Orbis Pictus" (El Mundo Visible en Ilustraciones), 1658, constituye la primera obra ilustrada para niños. Goethe recordaba sus lecturas de este libro durante su infancia.

\section{Internacionalización de la educación}

Comenius concebía una sociedad de la educación con vínculos en todo el mundo. Anhelaba una institución internacional que velara por ella y por la movilidad de estudiantes y profesores. Estas ideas quedan plasmadas hoy en la institucionalización de una organización internacional para la educación, como es UNESCO, y en diversos acuerdos y programas de la Unión Europea, como el acuerdo de Bologna, el Programa Comenius (promoción del intercambio de estudiantes secundarios de toda Europa) y el Programa Erasmus (intercambio de estudiantes universitarios). 


\section{Instrucción de acuerdo con las etapas de desarrollo de los alumnos}

Con relación a su metodología pedagógica, considera que la educación debe seguir a la naturaleza, "creadora de formas". El orden natural es el principio verdadero de enseñanza; la secuencia con la cual ocurre es, sin embargo, dinámica. Se puede considerar a Comenius como uno de los precursores de la instrucción progresiva de los alumnos de acuerdo con su desarrollo psicológico y cognitivo (Piaget, 1957).

En su "Gran Didáctica" propone cuatro tipos de escuelas para cada periodo o etapa de aprendizaje (infancia, niñez, adolescencia y juventud) y declara que en ellas se deben enseñar las mismas formas del conocimiento que corresponden a necesidades permanentes (Capek, 1957); la diferencia recae en la forma en que se realiza esa instrucción, que debe considerar la edad y desarrollo de los estudiantes y su nivel de aprendizaje (Capková, 1972). Señala además que el educador debe comprender cómo se desarrolla la mente del niño y cómo éste logra aprender.

\section{Palabras finales}

¿Conocerán nuestros estudiantes secundarios y universitarios o nuestros educadores los escritos de Comenius? ¿Conocerán estas ideas de una educación para todos, sin diferencias sociales, económicas, de credo, sexo, cultura? Algunos probablemente sí, otros tantos (desde la perspectiva de profesores universitarios), aunque no las conozcan a cabalidad, las intuyen y más de 350 años después les siguen motivando. Este intelectual checo sigue planteando interrogantes en torno a la función que corresponde a la sociedad como agente educador, ubicada en tiempo y espacio determinados. Es probable que la doctrina propuesta por Comenius no haya sido examinada aún con detención por sistemas emergentes que buscan la excelencia académica como un fin. 


\section{Referencias bibliográficas}

Capek, E. (1957) Jan Amos Komensky. Prague: Státní Pedagogické Nakladatelství.

Capková, D. (1972) Vzdelávání malých detí v pojetí universálniho celizivotniho vzdelává v dile J. A. Prague: Ed. Universita.

Cornej, R. y Pokorný, J. (2000) Dejiny Ceských zemí do roku 2000. Praha: Prah.

Denis, M. (1993) Comprendre Comenius. Paris: Presses Universitaires de France.

Frumov, S.A. (1953) Demokratické ideje Jana Amose Komenského a jeho soustava lidového vzdeláni. Prague: Státni Pedagogické Nakladatelstvi.

Piaget, J. (1957) Jean Amos Comenius 1592-1670. Pages choisis. Introduction de Jean Piaget. Paris: UNESCO.

Schaller, K. (1989) Komenskýs Auseinandersetzung mit dem Cartesianismus-eine neue Dimension der Aktualität seiner pansophischen Pädagogik. Symposium Comenianum. Prague: Academia.

Tenenti, A. \& Romano, R. (1983) Los fundamentos del mundo moderno. Edad Media, Renacimiento, Reforma. Madrid: Siglo XXI.

Velinger, Jan (2004, 6 de Julio) Jan Amos Comenius -The teacher of nations. Disponible en http://radio.cz/en/article/55618. Consultado el 5 de abril de 2008.

Recibido: 02 de octubre de 2008

Aceptado: 4 de noviembre de 2008 